\title{
Correction: HIF-1-dependent expression of angiopoietin-like 4 and L1CAM mediates vascular metastasis of hypoxic breast cancer cells to the lungs
}

\author{
H. Zhang - C. C. L. Wong - H. Wei - D. M. Gilkes • P. Korangath • P. Chaturvedi • L. Schito • J. Chen • \\ B. Krishnamachary • P. T. Winnard Jr • V. Raman - L. Zhen • W. A. Mitzner · S. Sukumar · G. L. Semenza
}

Published online: 15 January 2021

(c) The Author(s), under exclusive licence to Springer Nature Limited 2021

Correction to: Oncogene

https://doi.org/10.1038/onc.2011.365

Since publication of the article the authors noticed the following errors:

(1) The actin immunoblot (loading control) from Fig. 6B was mistakenly included in Fig. 6G. The correct actin immunoblot is attached. It demonstrates that there was equal loading in all of the lanes.
(2) The three panels in Fig. 1A (HIF-1alpha, HIF-2alpha, and actin immunoblots) are identical to three panels in Fig. 1B of Gilkes et al. (Cancer Res. 73:3285, 2013). These are validation immunoblots for knockdown subclones, which were generated through the combined effort of the first authors of the Oncogene and Cancer Research papers.

We regret the two errors that were made. They do not alter any of the paper's conclusions.

Fig. 1.

G

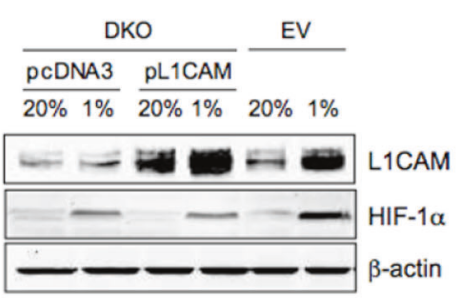

Figure 6G in the paper

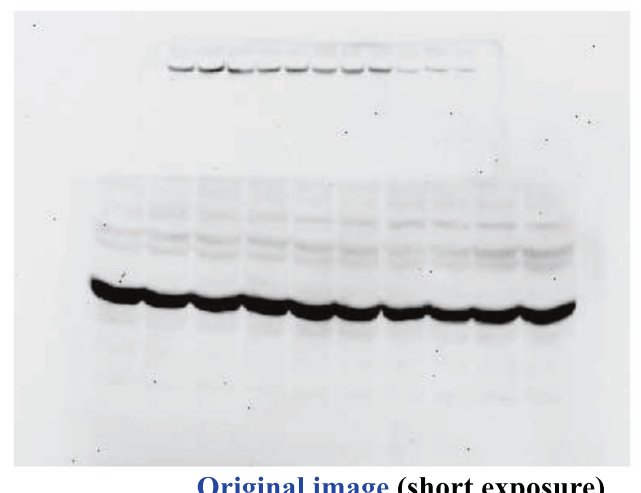

Original image (short exposure)
G

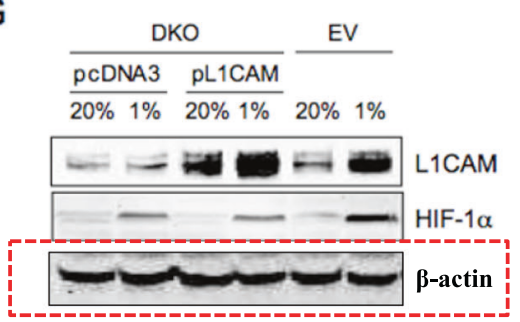

Corrected Figure 6G

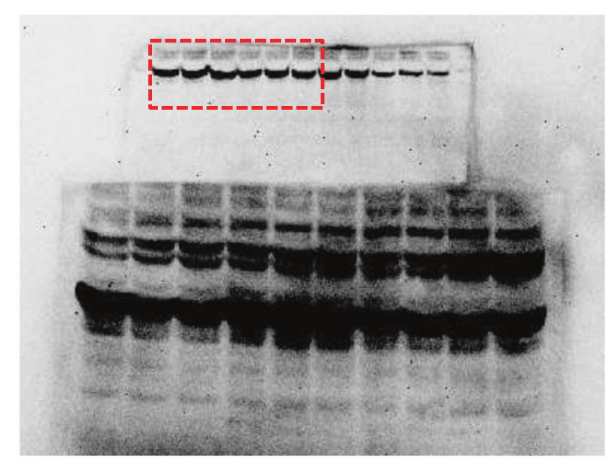

Original image (long exposure) 
Fig. 6 .

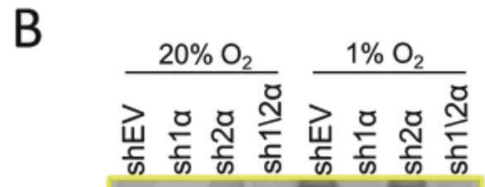
$\mathrm{HIF-1 \alpha \cdot 0}=$

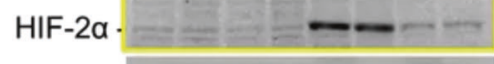

P4HA1 - $--1-\infty=$

$\mathrm{P} 4 \mathrm{HA} 2-+-1-2-1-$

Actin

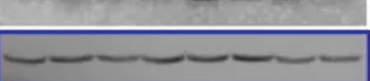

A $\frac{20 \% \mathrm{O}_{2}}{\text { EV } \operatorname{sh} 1 \alpha \operatorname{sh} 2 \alpha \text { DKD }} \frac{1 \% \mathrm{O}_{2}}{\text { EV } \operatorname{sh} 1 \alpha \operatorname{sh} 2 \alpha \text { DKD }}$

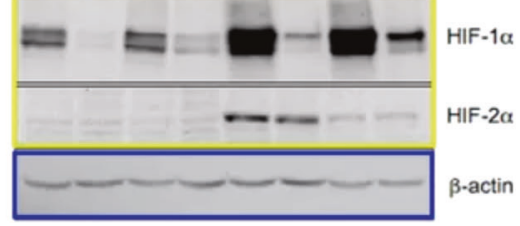

